ISSN: 2578-0255

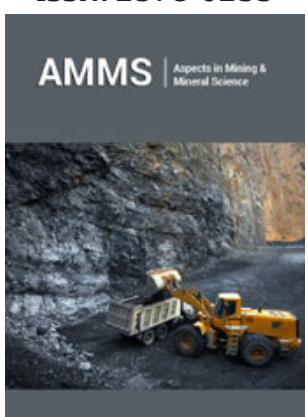

*Corresponding author: Jinhong Zhang, Department of Mining and Geological Engineering, University of Arizona, Tucson, USA

Submission: 侮 May 16, 2020

Published: 㙁June 18, 2020

Volume 5 - Issue 1

How to cite this article: Jinhong Zhang. Applying High Salinity Water in Flotation-A Review. Aspects Min Miner Sci. 5(1). AMMS.000604. 2020

DOI: 10.31031/AMMS.2020.05.000604

Copyright@ Jinhong Zhang, This article is distributed under the terms of the Creative Commons Attribution 4.0 International License, which permits unrestricted use and redistribution provided that the original author and source are credited.

\section{Applying High Salinity Water in Flotation-A Review}

\author{
Jinhong Zhang* \\ Department of Mining and Geological Engineering, University of Arizona, USA
}

\section{Abstract}

The paper reviewed the application of high salinity water in flotation. The materials, of which flotation process high salinity water was use, were classified as four different categories, i.e., ions, soluble salt minerals, coal and sulfide. The mechanism of high salinity's impact on flotation was also summarized.

Keywords: Mining; Salinity; Trace metals; Salt minerals; Flotation

\section{Introduction}

In mining industry, flotation consumes a large amount of fresh water, in spite of the fact that a portion of process water is recycled. Superficially it seems that there is no need to use fresh water for flotation because during flotation, water is mixed with rock which are "dirty". This raises the logical question whether low quality water, such as river water, reclaimed water and high salinity water (sea water and groundwater), can be used for flotation with no decrease in the efficiency of the process. The present review will focus on the application of high salinity water in flotation. In general, the flotation process using high salinity water can be classified as the following different categories:

\section{Flotation of trace heavy metal species in sea water}

Some trace elements, for example, vanadium, selenium and indium and so on, are believed to play a role in the marine biosphere. However, the significance and involvement of these trace heavy elements is not clear yet. Starting from 1970's, froth flotation began to be applied in analytical chemistry in the separation of a variety of trace ionic species in sea water to quantify these trace metals. The adsorption salt flotation technique was applied for the separation of vanadium and selenium from sea water [1,2]. Sonawane et al. [3] surveyed various surfactants for the flotation of iron (III), aluminum and indium hydroxide collector precipitates for concentrating trace heavy metals in sea water. It was recommended that a 1:3 mixture of sodium oleate and sodium dodecylsulfate gave stable foam-layer formation, which was believed to be essential to salt flotation and therefore a complete flotation. Cabezon et al. [4] used octadecyl amine as collector and Ferric hydroxide as co-precipitant to simultaneously separate copper, cadmium and cobalt from sea water by co-flotation.

Basically, specific cationic or anionic surfactant, called "collector", was added into sea water and the collector will adsorb on the trace species and render the surface hydrophobic. The hydrophobized trace metal species will attach to bubbles in sea water and rise up forming foam layer for a further removal. Usually, anionic collector is chosen from sodium oleate and sodium alkyl sulfate; while cationic collector is alkyl amine. MIBC is a common frother. Because of the very high recoveries of the trace species based on spiked sea water samples, this pre-concentration by flotation has the advantages of being fast, simple and accurate over the classical techniques such as co-precipitation, co-crystallization and ion-exchange, which have been employed to pre-concentrate trace metals in sea waters.

\section{Flotation of soluble salt minerals (potash, trona and borax) in saturated saline water}

Potash is very important for the growth of plants and it is generally used as fertilizer in agriculture. Sylvite, the most important potash mineral, is abundant in saline lake deposits. 
The water soluble potash mineral has to be separated from other soluble salt mineral, such as halite and so on, before being further processed and made into fertilizer [5]. Historically, flotation process was first applied in 1940's for the separation of two water soluble minerals, sylvite $(\mathrm{KCl})$ and halite $(\mathrm{NaCl})$, in their own saturated brine water and this event represented a milestone in the development of the flotation process. Now separation of watersoluble minerals by flotation is the most important present-day method of potash ore processing. In practice, both normal flotation and reverse flotation have been used for the separation of sylvite from halite [6]. Collector can be chosen from either cationic alkyl amine surfactant or anionic alkyl sulfate surfactant. Frother and conditioning agent are typically required for high flotation recovery and efficiency. Recently, a complete review work was published by Ozdemir et al. [7] showing that the ion specificity effect is the most important factor influencing salt flotation. In the specific work, the measurement such as solution viscosity, surface tension, bubbleparticle attachment time, contact angle, atomic force microscopy, sum frequency generation vibrational spectroscopy and molecular dynamics simulation have been used to study the air-solution and solid-solution interfacial phenomena.

\section{Flotation of coal using sea water}

The reason that sea water has been applied for coal flotation is mainly because in 1920 some coals were reported to be readily floated in sea water without the addition of reagents (collector and frother). In 1930's, the flotation of coal using sea water was further investigated by Russian researchers [8]. The technique was later developed and called salt flotation, in which a high concentration of inorganic electrolyte is employed. Many studies have been carried out since then and it has been proposed that salt flotation is generally applied for naturally hydrophobic minerals, particularly for coal. Klassen and Vlasova [9] studied the flotation of coals of different rank in the presence of $\mathrm{NaCl}$ and reported that sea water can be a good self-frothing media in coal flotation. Results showed that high-rank coals can be successfully treated in $\mathrm{NaCl}$ solutions; however, flotation of the low-rank coals required the addition of hydrocarbons (petroleum). Fuerstenau et al. [10] studied the effect of surface functional groups on the salt flotation of coal and claimed that salt flotation was sensitive to coal functional group and it failed completely for heavily oxidized coal. They proposed that flotation rate increased substantially with increasing salt concentration, although the position of the maximum in floatability with respect to $\mathrm{pH}$ did not change. It was reported that increasing electrolyte concentration would introduce a more rapid thinning and rupturing of the film between particle and bubble. Yoon and Sabey [11] reported that salt flotation was better than conventional flotation by introducing faster flotation kinetics and a higher separation efficiency of removing ash from bituminous coal. Results showed that the frothability of salt solution increased with increasing salt concentration and divalent cations salts gave the best flotation results.

$\mathrm{Li}$ and Somasundaran [12-14] studied the effect of $\mathrm{NaCl}$ on coal flotation using a modified Hallimond tube and Zeta potential meter to delineate the role of the electrostatic interaction between bubbles and particles. It was reported that, at low salt concentrations and high salt concentrations, flotation exhibited showed different behavior. Botula et al. [15] studied the effect of saline water on coal flotation and reported that no statistically significant effect of water salinity (salt concentration or composition) was observed. Iskra et al. [16] investigated the effect of mine water salinity on flotation of coal slurries from Budryk Mine and reported that water salinity improves flotation kinetics and reduces reagents consumption. Hampton and Nguyen [17] studied the accumulation of dissolved gases at hydrophobic surfaces in water and $\mathrm{NaCl}$ solutions and discussed its implications for coal flotation in saline water in terms of attraction between hydrophobic surfaces in water, bubble/particle attachment and hydrophobic coagulation between particles. They reported that $\mathrm{NaCl}$ concentration (up to $1 \mathrm{M}$ ) had a negligible influence on the geometry and population of pre-existing nanobubbles. Ozdemir et al. [18] focused on the surface chemistry aspects of coal flotation in bore water which was frequently used as process water in several flotation plants in Western Australia. Some surface chemistry techniques, such as bubble/particle attachment time experiment, zeta potential measurement, contact angle measurement and Atomic Force Microscopy (AFM) were applied to clarify the effect and mechanism of high salt/electrolyte concentrations.

\section{Flotation of sulfide minerals using high salinity water}

High salinity water has been applied for sulfide flotation generally in the arid areas such as Chile and Western Australia, where water is a precious commodity with little or no access sometimes. In practice, the concerns related to sulfide salt flotation are mainly focused on the impact of high salinity on flotation efficiency, the buildup of salt in recycled water and equipment corrosion. Sutulov [19] reported that successful flotation of copper minerals had taken place in Chile using sea water and the common buildup of dissolved mineral salts ( $\mathrm{Ca}, \mathrm{Mg}, \mathrm{Na}$ ) in recycled water was not a demonstrable problem. Vaughan and Dunne [20] studied the mineralogy and processing characteristics of Archean gold ores from Western Australia in highly saline ground water in the Yilgarn area. It was reported that the saline process water may interfere with processing in a variety of ways. For example, protective coatings were required because of the equipment corrosion problem in plants, arising from mainly the high $\mathrm{NaCl}$ content in groundwater. Wellham et al. [21] studied the role of carboxyl methyl cellulose in the flotation of a nickel sulfide transition ore. The hypersaline water used in the flotation plants was reported to make traditional serpentine dispersants ineffective.

Klimpel [22] claimed that sea water could be applied in flotation quite successfully. In addition, the hard water containing high levels of monovalent and divalent ions do not negatively affect the recovery and selectivity of water insoluble uncharged collectors with naturally floatable sulfide minerals. Rhodes and Penna [23] studied the flowsheet for the Sukari gold project, which is in one of the driest deserts in the world, in Egypt. The plant was designed to use sea water, which was pumped from the Red Sea $22 \mathrm{~km}$ from the 
mine site, in the process plant grinding, leach and flotation circuits. Actually, a proportion of the water was treated in a reverse osmosis plant to produce fresh water for the gold circuit, mine services and power plant. Peng et al. [24] carried out a research on the flotation of a low grade pentlandite (nickel sulfide) ore containing large amounts of serpentine minerals from Mt. Keith in Western Australia using high salinity process water. Moreno et al. [25] reported the use of seawater as process water at Las Luces copper-molybdenum beneficiation plant in Taltal (Chile). In Las Luces plant, seawater is mixed with tailings pond water and used in the grinding and flotation circuits. It was claimed that the plant had successfully used seawater for many years without the use of any fresh water and a loss of water to evaporation could be a problem. In Chile, [26] which is located in the Atacama Desert, one of the driest desert in the world, at an elevation of $2100 \mathrm{~m}$ above sea level became the first large-scale copper mine to only raw sea water in flotation.

\section{Mechanism of High Salinity's Impact on Flotation}

The difference between high salinity water and fresh water is mainly because the ionic strength in the former is much higher. Many investigations have been carried out to study the impact of high ionic strength on coal flotation in inorganic electrolyte solutions and several theories have been proposed. Firstly, the inorganic electrolytes can prevent bubble coalescence which leads to reduced bubble size and increased population. These will further increase bubble-particle attachment efficiency and froth stability, hence flotation efficiency $[11,27,28]$. Secondly, it was proposed that high ionic strength may compress the electrical double layer (EDL) between bubbles and particles and therefore reduce the zeta potential of both bubbles and particles. The theory was supported by some experiment results showing that the flotation recovery achieved a maximum at a minimum zeta potential $[10,11]$. Thirdly, Klassen and Mokrousov [29] suggested that the inorganic electrolytes reduced the surface hydration of coal and destabilized the hydrated layers surrounding coal, which made the coal more hydrophobic and enhanced the bubble-particle attachment. However, this mechanism broke down in the case of naturally hydrophilic minerals, the flotation of which was not improved by the presence of high ionic strength.

\section{Summary}

The above review of using high salinity water in flotation shows that: 1) technically saline water can substitute for fresh water and be used in a large scale in flotation even without desalinization; 2) the impact of high salinity's impact on flotation could be multifold. For some flotation systems, high salinity water increases flotation performance; while it does reversely in other cases; 3) the mechanism of high salinity's impact on flotation depends on various conditions, such as ore type, ions species, ionic strength, $\mathrm{pH}$, surface potential and others. As such, in practice, high salinity water may impact flotation in a complex way and it requires a systemic study for a specific case. An important prerequisite for this is that the chemistry of high salinity water will not evidently decrease flotation recovery and efficiency.

\section{References}

1. Hagadone M, Zeitlin H (1976) The separation of vanadium from sea water by adsorption colloid flotation. Analytica Chimica Acta 86: 289292.

2. Tzeng JH, Zeitlin H (1978) The separation of selenium from sea water by adsorption colloid flotation. Analytica Chimica Acta 101(1): 71-77.

3. Sonawane NJ, Hiraide M, Mizuike A (1983) Combined use of two surfactants for flotation of metal hydroxide precipitates in sea water. Analytica Chimica Acta 149: 359-362.

4. Cabezon LM, Caballero M, Cela R, Perez JA (1984) Simultaneous separation of copper, cadmium and cobalt from seawater by flotation with amine and ferric hydroxide as collectors. Talanta 31(8): 597-602.

5. DeVaney FD (1999) Flotation. Industrial and Engineering Chemistry 38(1).

6. Titkov S, Panteleeva N, Chistyakov Pimkina AL, Mikhaylova I (2000) Studies of surface and sorption behavior of saline and clay carbonate minerals in electrolytes. Proceedings of the XXI International Mineral Processing Congress, Rome, Italy. pp. 23-27.

7. Ozdemir O, Du H, Karakashev S, Nguyen A, Celik MS, et al. (2011) Understanding the role of ion interactions in soluble salt flotation with alkylammonium and alkylsulfate collectors. Advances in Colloid and Interface Science 163(1): 1-22.

8. Luisenko PD (1935) Enrichment of the long-flame coals of LIS sitchansk by flotation with salts. Coke and Chem 5(10): 40-46.

9. Klassen VI, Vlasova NS (1963) The effect of reagents in coal flotation. J of Mining Science 3(5): 504-510.

10. Fuerstenau DW, Rosenbaum JM, Laskowski J (1983) Effect of surface functional groups on the flotation of coal. Colloid and Surfaces 8(2): 153-173.

11. Yoon RH, Sabey JB (1989) Coal flotation in inorganic salt solution. In: Botsaris GD, Glazman YM (Eds.), Interfacial phenomena in Coal Technology. Marcel Dekker, New York. pp. 87-114.

12. Li C, Somasundaran P (1991) Reversal of bubble charge in multivalent inorganic salt solutions-effect of magnesium. J Colloid Interface Sci 146(1): 215-218.

13. Li C, Somasundaran P (1992) Effect of $\mathrm{NaCl}$ on coal flotation. SME Annual Meeting Phoenix, Arizona, USA. pp. 24-27.

14. Li C, Somasundaran P (1993) Role of electrical double layer forces and hydrophobicity in coal flotation in sodium chloride solutions. Energy Fuels 7(2): 244-248.

15. Botula J, Repka V (1996) Effect of saline water on flotation processing of coal. Uhli-Rudy-Geol Pruzkum 3(1): 13-14.

16. Iskra J (1996) Effect of mine water salinity on flotation of coal slurries from the Budryk mine. Zesz Nauk Politech Slask Gom 231: 237-252.

17. Hampton MA, Nguyen AV (2009) Accumulation of dissolved gases at hydrophobic surfaces in water and sodium chloride solutions: Implications for coal flotation. Minerals Engineering 22(9-10): 786-792.

18. Ozdemir O, Taran E, Hampton MA, Karakashev SI, Nguyen AV (2009) Surface chemistry aspects of coal flotation in bore water. Int J Miner Process 92(3-4): 177-183.

19. Sutulov A (1963) Flotation of minerals. Chile. pp. 124-126.

20. Vaughan JP, Dunne RC (1987) Mineralogy and processing characters of Archen gold ores from Western Australia. Gold Mining, Australia. pp. 241-256.

21. Wellham EJ, Elber I, Yan DS (1992) The role of carboxyl methyl cellulose in the flotation of a nickel sulphide transition ore. Miner Eng 5(3-5): 381-395. 
22. Klimpel R (1999) A review of sulfide mineral collector practice. In: Parekh BK, Miller JD (Eds.), Advances in Flotation Technology, USA.

23. Rhodes M, Penna F (2009) Flowsheet development for the Sukari gold project in Egypt. World Gold Conference 2009. The Southern African Institute of Mining and Metallurgy, Australia. pp. 279-286.

24. Peng Y, Seaman D (2011) The flotation of slime-fine fractions of Mt. Keith pentlandite ore in de-ionised and saline water. Minerals Engineering 24(5): 479-481.

25. Moreno PA, Aral H, Cuevas J, Monardes A, Adaro M, et al. (2011) The use of seawater as process water at Las Luces copper-molybdenum beneficiation plant in Taltal (Chile). Minerals Engineering, Chile.
26. Esperanza mine (2011) CESCO: Chile Antofagasta's Esperanza Gets Creative with Seawater.

27. Yoon RH (1982) Flotation of coal using micro-bubbles and inorganic salts. Min Congr J 68(12): 76-80.

28. Paulson O, Pugh RJ (1996) Flotation of inherently hydrophobic particles in aqueous solutions of inorganic electrolytes. Langmuir 12(20): 48084813.

29. Klassen VI, Mokrousov VA (1963) An introduction to the theory of flotation. In: Leja J, Poling GW (Eds.), Butterworths, London. 